\title{
Ring chromosome 11 syndrome
}

INSERM

\section{Source}

INSERM. (1999). Orphanet: an online rare disease and orphan drug data base. Ring chromosome 11 syndrome. ORPHA:96175

Ring chromosome 11 syndrome is an autosomal anomaly characterized by variable clinical features, including early growth retardation and short stature, microcephaly, developmental delay, some degree of intellectual disability, facial dysmorphism and caféau-lait spots. In some cases, congenital heart disease and endocrine abnormalities have been reported. 